\title{
The Impact of Being Envied on Work Engagement: A Test of the Transactional Model of Stress and Coping
}

\author{
Huang Qing \\ Department of Human Resource Management \\ Nanjing University \\ Nanjing, China
}

\author{
Tao Xiangnan \\ Department of Human Resource Management \\ Macau University of Science and Technology \\ Macau, China
}

\author{
Jiang Chunyan* \\ Department of Human Resource Management \\ Nanjing University \\ Nanjing, China
}

\begin{abstract}
Over the years, how employees have responded to workplace envy has been a puzzling question. Using the transactional model of stress and coping, we explore the moderating role of that Zhong-Yong thinking and two coping styles in the relationship between being envied and work engagement from the perspective of cultural fit. A survey of 303 employees was conducted. Empirical results indicate that the relationship between being envied and work engagement is weaker for employees with high Zhong-Yong thinking. Futhermore, the mediated moderation analysis shows that Zhong-Yong thinking is positively associated with both positive coping styles and negative coping styles. Specifically, the moderating effects of Zhong-Yong thinking between being envied and work engagement are mediated by negative coping styles. The findings extend the previous studies on the relationship between being envied and work engagement by exploring the boundary effects, reveal how Zhong-Yong thinking affects work engagement, and confirm the notion that coping styles might be the key mediator through how Zhong-Yong thinking works.
\end{abstract}

Keywords-Being envied; Zhong-Yong thinking; Coping styles; Work engagement; Transactional model of stress and coping

\section{INTRODUCTION}

Whether task assignment, job changes, salary adjustment, or leader-member exchange, many events in the workplace will induce workplace envy[1]. Some studies have found that the envied people will have the ambivalent affective experience[2,3], but few scholars have delved into behavioral responses of the being envied [1,4]. Therefore, Exline (2013), Liu (2018) and other scholars called for changing mind and exploring deeply what behavioral responses of the being envied may have, what factors will affect these behavioral responses, and whether different coping styles have different effects[1,2]. To answer the scholars' calling, we apply the transactional model of stress and coping strategies model(TMSC) to explore the role of thinking styles in determining how the employees respond to being envied, and examine the process through which these moderating effects occur.

\section{LITERATURE REVIEW AND HYPOTHESES}

\section{A. Being Envied and Work Engagement}

Although envied employees may experience two completely opposite emotions, when being envied causes unpleasantness, it will cover up and gradually replace shortterm positive emotions, and affect employees' work engagement in a negative way[3]. On the one hand, when employees perceive themselves as the target of another person's envy, they not only experience tension and anxiety, but also have to consider coping strategies, which will consume a lot of time and energy. Considering that one's energy is limited, when employees are invested too much in workplace envy, the vitality and vigor in work will be reduced accordingly. On the other hand, some employees may take the initiative to reduce work engagement in order to avoid being the "target" of others' attacks[3]. In addition, Ma, Huang and Zhu (2014) also found that interpersonal relationship pressure will negatively affect the performance of employees. Therefore, we propose the following assumption:

H1: Being envied has a negative impact on the work engagement of the envied.

\section{B. The Moderating Effect of Zhong-Yong Thinking}

Compared with other cultural values of the Chinese people, Zhong-Yong thinking involves all aspects of interpersonal interaction. Under the envied circumstance, people with high Zhong-Yong thinking tend to regard this interpersonal relationship pressure as temporary pressure or temporary illusion. After considering the consequences of actions, they often adopt a "unchanged" approach, which means tolerance of apparent contradictions, and avoidance of extremities. As a

National Natural Science Foundation of China 71872084 
result, the mental and physical reactions caused by being envied are lagging behind, and their work engagement may not be significantly negatively affected. In contrast, individuals with low Zhong-Yong thinking will not compromise easily, tend to amplify the negative feelings of being envied, and even be more sensitive to the words and deeds of the envious. In order to change the adverse environment, they often break the current state upon impulse. But once the judgment is wrong or the envious person firmly denies it, it will intensify the interpersonal conflict between the envious person and the envied person, then affect the working state of both sides. Therefore, employees with low Zhong-Yong thinking have a negative cognitive evaluation and stress response to being envied, which will further strengthen the negative impact of being envied on work engagement. To sum up, we put forward the following assumption:

H2: Zhong-Yong thinking moderates the relationship between being envied and work engagement. For employees with high Zhong-Yong thinking, their work engagement will be more influenced by being envied than employees with low Zhong-Yong thinking.

\section{Zhong-Yong Thinking and Coping Styles}

According to TMSC, there are two processes-cognitive appraisals and coping-in the relationship between person and environment. In the secondary appraisal stage, individuals will evaluate which coping strategies can eliminate the negative effects of stressors [5].

As discussed above, the individual's value orientation and thinking mode can affect the behavioral response to being envied. Employees with different values have different cognitive evaluations and coping strategies for being envied[1]. As one of the most typical thinking pattern in China, ZhongYong thinking is the guiding value of the Chinese people in dealing with interpersonal relationships[6]. This mode of thinking can help individuals deal with the interpersonal relationships with an eye to the interests of the whole. According to Sun, Yan and Chu (2014), employees with high Zhong-Yong thinking are good at handling conflicts and tend to take all the behavioral consequences into consideration. For them, the choice of tolerance can help them achieve the goal of harmony. However, employees with low Zhong-Yong thinking are more likely to seek comfort from others or seek solutions from others, and less likely to consider whether such positive actions will intensify interpersonal conflicts with envious people. Therefore, for those envied people with Zhong-Yong thinking, adopting positive coping loses more than gains, which is contrary to their goal of pursuing interpersonal harmony. Accordingly, we put forward the following assumptions:

H3: Zhong-Yong thinking is negatively related to individuals' positive coping styles.

H4: Zhong-Yong thinking is positively related to individuals' negative coping style.

\section{Moderating Effect of Coping Styles}

Due to the hidden nature of workplace envy, interpersonal conflicts between the envious and the envied have not yet been intensified. If the envied employees take positive approaches, they will not only spend their time and energy, but also may be denied and attacked by the envious. Because this way of coping means to expose the negative emotions hidden by the envious. In some case, rash actions will affect the work status of both sides. Instead, trying to forget the whole thing or reduce the contact with the envious person can not only alleviate the stress and anxiety of being envied, but also minimize the impact of being envied on their work state. Therefore, we believe that positive coping may enhance the negative effect of being envied on work engagement, and negative coping may weaken the negative effect of being envied on work engagement.

H5: Positive coping styles moderate the relationship between being envied and work engagement. For employees who choose positive coping styles, their work engagement will be more influenced by being envied than employees who choose negative coping styles.

H6: Negative coping styles moderate the relationship between being envied and work engagement. For employees who choose negative coping styles, their work engagement will be less influenced by being envied than employees who choose positive coping styles.

\section{E. Mediated Moderating Effect}

The above assumptions meet the requirements of the mediated-moderation model by Grant and Berry(2011). Therefore, we infer that the two coping styles mediate the moderating effect of Zhong-Yong thinking on the relationship between being envied and work engagement.

H7: Positive coping mediates the moderating effect of Zhong-Yong thinking on the relationship between being envied and work engagement.

H8: Negative coping mediates the moderating effect of Zhong-Yong thinking on the relationship between being envied and work engagement.

\section{METHOD}

\section{A. Experimental Design}

We conduct our survey in two phases. In the first phase, questionnaires containing the measures of control variables, independent variables and moderator variables were distributed to employees in workplace. In order to improve the efficiency of investigation, we use the electronic questionnaire to investigate the dependent variable in the second phase. The two questionnaires were matched by employee number.

\section{B. Sample Description}

303 employees from a private enterprise in Nanjing, an eastern city of China, participated in the experiment. Among the 303 employees, $63.000 \%$ of respondents were female; The average of education was 13.419 years $(\mathrm{SD}=1.332)$; The mean organizational tenure was 2.481 years $(\mathrm{SD}=2.436)$. The 
age of the sample ranged from 18 to 43 years $(M=27.089$, SD $=4.361$ ).

\section{Measurements}

A three-items scale developed by Vecchio (2005) was used to measure being envied[7]. A eighteen-item scale developed by $\mathrm{Du}$ and Yao (2015) was used to measure Zhong-Yong thingking[6]. A twenty-item scale developed by Xie (1998) was used, in which there were 12 positive coping styles and 8 negative coping styles[8]. A seventeen-item scale developed by Schaufeli (2002) was used to measure work engagement[9]. Participants' gender, age, educational level, and work duration are control variables.

\section{Analytical Strategies}

We employed Amos 17.0.2 to check the validity of our measures by conducting the confirmatory factor analysis. Then we tested the hypothesized moderation effects following hieratical regression procedures by Aiken and West (1991) [10].

\section{RESULTS}

\section{A. Factor Analysis}

CFA results showed that our proposed five-factor (being envied, Zhong-Yong thinking, two coping types and work engagement) model achieved a good model fit in terms of all fit indices, with $\chi^{2}(395)=818.740$, RMSEA of 0.062 , IFI of 0.891 , CFI of 0.890 , and TLI of 0.879 .

\section{B. Hypotheses Testing}

Regression analysis was used to test all the hypotheses. The regression results of model 3 in table 2 showed that being envied was significantly negatively related to work engagement $(\beta=-0.387, p<0.001)$. So hypothesis 1 was supported. Results of regression analysis in model 5 showed that this moderation effect was significant for work engagement $(\beta=0.179, p<0.01)$. Hypothesis 2 was supported. Figure 1 shows a clearer picture of the moderation effect. The negative relationship between being envied and work engagement is weaker for employees with high Zhong-Yong thinking, and the negative relationship between being envied and work engagement is stronger for employees with low Zhong-Yong thinking. The regression results of model 1 and model 2 in table 1 showed that Zhong-Yong thinking had a significant positive effect on both positive coping styles $(\beta=$ $0.172, p<0.01)$ and negative coping styles $(\beta=0.157, \mathrm{p}<0.01)$. Thus, hypotheses 3 was not supported, and the hypothesis 4 was supported. Results of regression analysis in model 6 showed that the moderation effect of positive coping styles on work engagement was not significant $(\beta=0.039, p>0.05)$. Hypothesis 5 and 7 were not supported. While the moderation effect of negative coping styles on work engagement was significant $(\beta=0.124, \mathrm{p}<0.05)$. Hypothesis 6 was supported. Figure 2 shows a clearer picture of the moderation effect of negative coping styles. The more often envied employs adopt negative coping styles, the weaker of the negative relationship between being envied and work engagement. In addition, results of regression analysis in model 6 also showed that the moderation effect of Zhong-Yong thinking was significant $(\beta=0.124, p<0.05)$ when the moderation effect of negative coping styles was significant $(\beta=0.119, \mathrm{p}<0.05)$. Thus, the moderation effect of Zhong-Yong thinking between being envied and work engagement was partly mediated by negative coping styles. Hypothesis 8 was supported.

To verify whether the moderation effect of Zhong-Yong thinking works via coping styles, this paper adopts the Bootstrap method proposed by Grant and Berry (2011). The results showed that the indirect effect of Zhong-Yong thinking via positive coping styles on the relationship between being and work engagement was positive(estimate $=0.05,90 \% \mathrm{CI}$ $[-0.07,0.16]$ including 0). Hypothesis 7 was not supported. And the results showed that the indirect effect of Zhong-Yong thinking via negative coping styles on the relationship between being and work engagement was positive(estimate = $0.10,90 \%$ CI $[0.02,0.18]$ excluding 0$)$. Hypothesis 8 was supported.

TABLE I. HIERARCHICAL REGRESSION RESULTS $(\mathrm{N}=303)$

\begin{tabular}{|c|c|c|}
\hline & PCS & NCS \\
\hline Variable & $\boldsymbol{M 1}$ & $\boldsymbol{M 2}$ \\
\hline Constant & $2.822^{* * *}$ & $2.080^{* *}$ \\
\hline Gender & -0.070 & 0.016 \\
\hline Age & -0.021 & -0.036 \\
\hline Education & -0.017 & -0.093 \\
\hline Length of service & $-0.244^{* * *}$ & 0.012 \\
\hline Zhong-Yong thinking & $0.172^{* *}$ & $0.157^{* *}$ \\
\hline $\mathrm{R}^{2}$ & $0.098^{* * *}$ & $0.036^{*}$ \\
\hline
\end{tabular}

TABLE II. HIERARCHICAL REGRESSION RESULTS $(\mathrm{N}=303)$

\begin{tabular}{|c|c|c|c|c|}
\hline & \multicolumn{4}{|c|}{ Work Engagement } \\
\hline Variable & M3 & M4 & M5 & M6 \\
\hline Constant & $3.840 * * *$ & $3.685 * * *$ & $3.284 * * *$ & $3.268 * * *$ \\
\hline Gender & 0.052 & 0.057 & 0.051 & 0.070 \\
\hline Age & 0.069 & 0.070 & 0.053 & 0.057 \\
\hline Education & 0.038 & 0.040 & 0.052 & 0.044 \\
\hline Length of service & -0.113 & -0.111 & -0.099 & -0.033 \\
\hline Being envied & $-0.387 * * *$ & $-0.391 * * *$ & $-0.393 * * *$ & $-0.331 * * *$ \\
\hline ZY & & 0.031 & -0.034 & -0.065 \\
\hline Being envied*ZY & & & $0.179 * *$ & $0.119 *$ \\
\hline PCS & & & & $0.297 * * *$ \\
\hline NCS & & & & -.088 \\
\hline Being envied* PCS & & & & 0.039 \\
\hline Being envied* NCS & & & & $0.124 *$ \\
\hline$\triangle \mathrm{R} 2$ & & & $0.028 * * *$ & $0.105 * * *$ \\
\hline
\end{tabular}

$\mathrm{ZY}=$ Zhong-Yong thinking, PCS $=$ Positive coping styles, $\mathrm{NCS}=$ Negative coping style. 


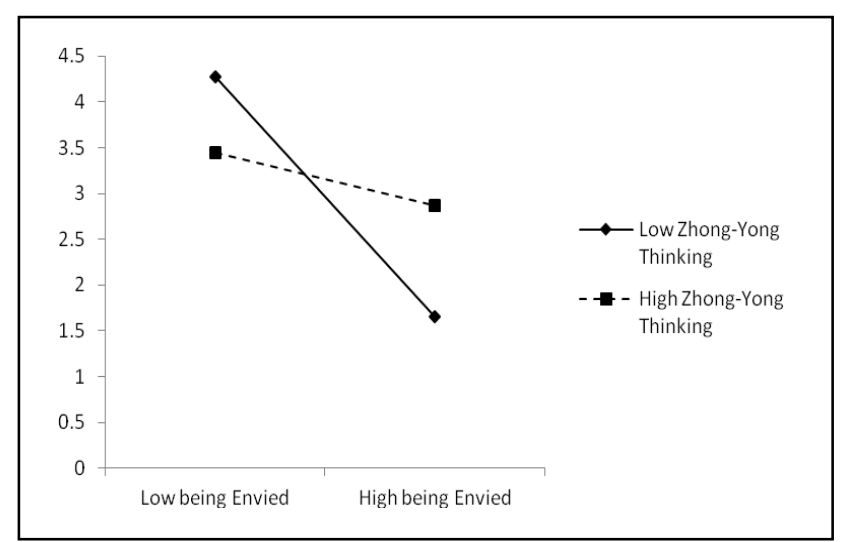

Fig. 1. Interactional effect of Zhong-Yong thinking and being envied on work engagement

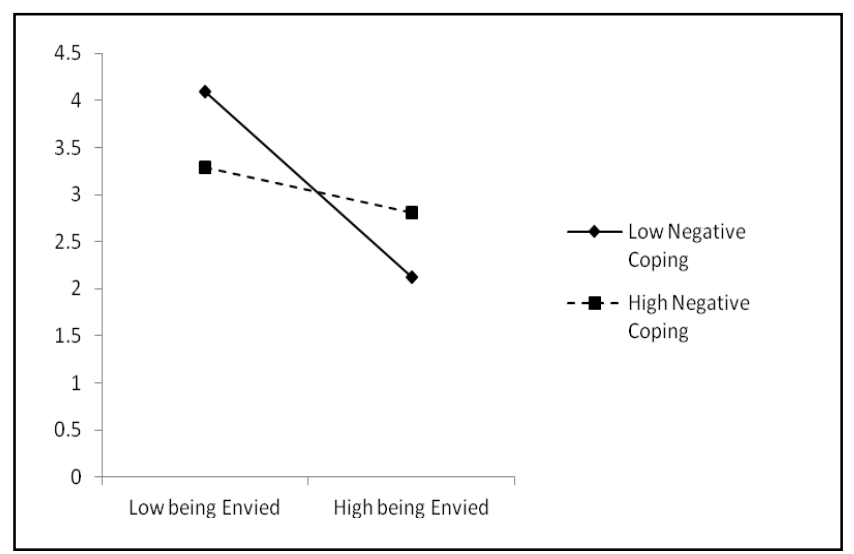

Fig. 2. Interactional effect of negative coping styles and being envied on work engagement

\section{CONCLUSION}

Based on TMSC, We find that coping styles will influence the moderation effects of Zhong-Yong thinking on the relationship between being envied and work engagement. The results suggest that the extent to which Zhong-Yong thinking moderates the relationship between being envied and work engagement varies from the coping styles they choose.

This paper demonstrates that Zhong-Yong thinking of Chinese employees will effectively reduce the negative impact of being envied on job engagement, shows the positive significance and epochal vigor of Chinese traditional culture. Furthermore, the empirical evidence discussed above supports our prediction that negative coping styles would relieve workplace envy stress and lessen the negative impact of being envied on work engagement, which verifies the rationality of some negative coping styles. For those who are envied in the workplace, it is a good idea to bear patiently and abreact adequately. As Xie(1998) pointed that positive coping styles do not necessarily have positive effects, and negative coping styles do not necessarily have negative consequences[8]. On the other hand, our work also sets up a bridge between TMSC and STTUC. The finding that negative responses can reduce the negative effects of being envied supports the assertion of STTUC(sensitivity about being the target of a threatening upward comparison). When people believe that they are the target of another person's envy due to his/her excellent performance, they may experience unpleasant feelings or concern that has been termed Sensitivity to being the Target of a Threatening Upward Comparison (STTUC)[2]. Avoiding contact with the outperformed person is a good way to manage this phenomenon in the workplace and reduce STTUC discomfort. Thus, this paper provides compelling evidence that positive and negative coping styles work differently in the workplace envy context.

\section{ACKNOWLEDGMENT}

We would like to thank Lvyi Zhang, Yunjie Jiang and Fuli Sun for their helpful suggestions.

\section{REFERENCES}

[1] D. Liu, X. Huang, W. Chen, and W. Li, "Being envied: An ambivalent affective experience," Advances in Psychological Science, vol. 26, pp. 118-133, 2018. (references) . (In Chinese)

[2] J. J. Exline, A. L. Zell and M. Lobel, "Sidestepping awkward encounters avoidance as a response to outperformance-related discomfort," Journal of Applied Social Psychology, vol. 43, 706-720, 2013. (references)

[3] K. Lee, M. K. Duffy, K. L. Scott and M. C. Schippers, "The experience of being envied at work: How being envied shapes employee feelings and motivation," Personnel Psychology, vol. 71, pp 181-200, 2018. (references)

[4] H. Puranik, J. Koopman, H. C. Vough, and D. L. Gamache, "They Want What I've Got (I think): The Causes and Consequences of Attributing Coworker Behavior to Envy," unpublished.

[5] R. S. Lazarus and S. Folkman, "Transactional theory and research on emotions and coping," European Journal of Personality, vol. 3, pp 141169, 1987. (references)

[6] J. Du and J. Yao, "Zhongyong: The connotation and its relationship with collectivism," Chinese Journal of Management, vol. 12, pp 638-646,. 2015. (references) .(In Chinese)

[7] R. Vecchio, "Explorations in employee envy: Feeling envious and feeling envied," Cognition and Emotion, vol. 19,no. 1, pp. 69-81, 2005. (references)

[8] Y. Xie, "A preliminary study on the reliability and validity of the simple coping style scale," Chinese Journal of Clinical Psychology, vol. 6, pp. 53-54, 1998. (references).(In Chinese)

[9] W. B. Schaufeli, M. Salanova, V. Gonzalez-Roma and A. B. Bakker, "The Measurement of Engagement and Burnout: a two sample Confirmatory Factor Analytic Approach," Journal of Happiness Studies, vol. 3, pp. 71-92, 2002. (references)

[10] L. S. Aiken and S. G. West, Multiple regression: Testing and interpreting interactions. Newbury Park, CA: Sage Publications, 1991. 